\title{
Symptom Profile of Patients with Psychotic Disorders
}

\author{
Nepal $\mathbf{S}^{1}$, Gupta $\mathbf{D}^{2}$, Neupane $\mathbf{D}^{2}$ \\ 1. Assistant Professor, Department of Psychiatry, BPKIHS, Dharan, Nepal 2. MBBS Student, BPKIHS, \\ Dharan
}

E-mail *Corresponding author : surajnepal51@gmail.com

\begin{abstract}
Introduction: According to WHO, schizophrenia is a severe mental disorder affecting about 23 million people worldwide. Psychoses, including schizophrenia, are characterized by distortions in thinking, perception, emotions, language, sense of self and behavior. The impacts of these disorders are severe, with approximately 1 million people committing suicide annually. There is also an increase in co morbidity of these different conditions. So, this study was carried out to assess the symptom profile of patients with schizophrenia and other psychotic disorders (excluding mood disorders, substance induced psychotic disorders, organic psychotic disorders).
\end{abstract}

Material And Method: Discharge record sheets of all cases admitted (Total 86) to the psychiatric ward over the study period were reviewed. Cases diagnosed as schizophrenia and other psychotic disorders were enrolled. Major symptoms were listed from the discharge papers.

Results: Out of the total number of patients enrolled in the research, $68.6 \%$ were male while $31.4 \%$ were female. The mean age of the patients was found to be 31.03 years with a minimum age of 16 years and maximum 63 years. Most were from lower middle class family, Hindu by religion and unmarried. Among 86 cases, 26(30.2\%) were diagnosed as Unspecified nonorganic psychosis, 24(27.9\%) as Schizophrenia, 19(22.1\%) as Schizoaffective disorder, $14(16.3 \%)$ as Acute \& Transient Psychotic Disorder, 3(3.5\%) as Persistent delusional disorder. Delusion of persecution was present in 46 cases (53.5\%), Delusion of reference in 33 cases (38.4\%) and Hallucinations in 32 cases $(37.2 \%)$. Out of the 86 patients enrolled in the study, $15(17.4 \%)$ had at least one suicidal attempt.

Conclusion: Significant number of patients were diagnosed as Schizophrenia which is itself a chronic, debilitating illness. Hallucinations and delusions were present in most of the cases

Keywords: Schizophrenia, Hallucination, Delusion

\section{INTRODUCTION}

According to $\mathrm{WHO}$, schizophrenia is a severe mental disorder affecting about 23 million people worldwide. Psychoses, including schizophrenia, are characterized by distortions in thinking, perception, emotions, language, sense of self and behavior. ${ }^{1}$ The impacts of these disorders are severe, with approximately 1 million people committing suicide annually. There is also an increase in co morbidity of these different conditions. Psychotic disorders thus comprise a wide variety of disorders, some of which may not be acknowledged as ailment by many in the society, but still causing a lot of trouble to the sufferers and affecting the productivity of the persons and obviously of the nation. Moreover, the age group which is occupationally more active seems more affected by the disorders, many of which actually have good prognosis, suggesting the need for early identification and prompt management of these illnesses. These disorders are mostly stigmatized in our communities and this affect the overall care of mental health care users.

Although attempts have been made eminent psychiatrists in the past, the mental health professionals and policy makers in the country 
still find it difficult to obtain reliable information regarding psychiatric morbidity in the country, both in the community and hospitals. All those inconsistencies may be because of the difference in methods and methodology used; the setup, subject enrolled in the study and diagnostic criteria used. Despite of all those inconsistencies their findings are always helpful for both the health care providers and policy makers to formulate a necessary policy and plan of action to encounter the difficulties and to improve the quality of mental health services in the country. Similarly many of available studies in mental health in Nepal mostly describes about the people living in the capital city of Nepal and nearby cities, and their findings may also not likely to be generalized. Hence this present study is carried out to in-patients of B.P. Koirala Institute of Health Sciences (BPKIHS), Dharan, just as an attempt to enrich the available literature in the country in regards to sociodemographic characteristics and clinical profile of patients with schizophrenia and other psychotic disorders at a tertiary level hospital in eastern part of Nepal.

\section{MATERIAL AND METHOD}

This is a hospital based retrospective descriptive study. This study was carried out after getting ethical clearance from Departmental Research Unit (DRU) of Department of Psychiatry, BPKIHS. Patients admitted in Psychiatry ward from 01 April 2017 to 31 March 2018 fulfilling the inclusion criteria were enrolled for the study. This was done by reviewing discharge record sheets of all cases admitted to the ward over the study period. Cases diagnosed as schizophrenia and other psychotic disorders as per ICD-10 criteria were enrolled whereas psychosis due to mood disorders, substance induced psychotic disorders, organic psychotic disorders were excluded. There were 86 cases and data were recorded using semi structured proforma. Confidentiality was maintained throughout the study.

\section{RESULT}

Out of the total number of patients enrolled in the research, $68.6 \%$ were male while $31.4 \%$ being female. The mean age of the patients was found to be 31.03 years with a minimum age of 16 years and maximum 63 years. 59.3\% of them belonged to low middle class family, $40.7 \%$ belonged to lower class whereas none of them were of middle or upper class status. Among the 86 patients enrolled, $91.86 \%$ were Hindu, 5.81\% were Kirat, $1.16 \%$ were Muslim and remaining $1.16 \%$ belonged to other religion. Majority of them were Brahmin $33.72 \%$ followed by Madhesi $11.63 \%$, Limbu 11.63\%, Rai $10.47 \%$, Chhetri $6.98 \%$ and others. $48.84 \%$ of them were unmarried, $41.86 \%$ were married, $6.98 \%$ were separated and $2.33 \%$ were divorced. $58.14 \%$ of the patients were unemployed, $31.40 \%$ were student, $6.98 \%$ were farmer, $1.16 \%$ were homemaker and remaining $2.33 \%$ were nongovernment employee.

The mean age at onset of the illness was found to be 25.31 years with minimum age of 13 years and maximum age being 61 years. Most of the patients i.e. $49(57 \%)$ had the onset of the illness in the age interval of $16-25$ years.

Out of the 86 patients, $15(17.4 \%)$ had at least one suicidal attempt. Substance use was found in $37(43 \%)$ patients with nicotine in $33(38.4 \%)$ patient, alcohol in $22(25.6 \%)$ patients and cannabis in $13(15.1 \%)$ patients.

Among 86 cases enrolled in the research, $26(30.2 \%)$ were diagnosed as Unspecified nonorganic psychosis, $24(27.9 \%)$ as Schizophrenia, $19(22.1 \%)$ as Schizoaffective disorder, $14(16.3 \%)$ as Acute \& Transient Psychotic Disorder, 3(3.5\%) as Persistent delusional disorder according to the International Classification of Disease (ICD-10) ${ }^{7}$ of mental and behavioral disorders.

Among the total number of patients, 40 (46.5\%) had insidious onset, $35(40.7 \%)$ had acute onset and $11(12.8 \%)$ had abrupt onset of the illness.

The course of the illness was continuous in 72 $(83.1 \%)$ patients, continuous with waxing and waning in $5(5.8 \%)$ patients, episodic with complete inter-episodic remission in $7(8.1 \%)$ patients and episodic with incomplete interepisodic remission in $2(2.3 \%)$ of them. 
Table 1: Symptoms Present in the Patients enrolled in the Study

\begin{tabular}{|l|c|c|}
\hline \multicolumn{1}{|c|}{ Symptoms } & $\begin{array}{c}\text { Frequency } \\
(\mathrm{n}=86)\end{array}$ & Percentage \\
\hline Disturbed Sleep & 52 & $60.5 \%$ \\
\hline $\begin{array}{l}\text { Delusion of } \\
\text { Persecution }\end{array}$ & 46 & $53.5 \%$ \\
\hline Decreased Functioning & 44 & $51.2 \%$ \\
\hline Irritability & 37 & $43.0 \%$ \\
\hline Delusion of Reference & 33 & $38.4 \%$ \\
\hline $\begin{array}{l}\text { Auditory } \\
\text { Hallucination } \\
\text { (All Variety) }\end{array}$ & 32 & $37.2 \%$ \\
\hline Fearfulness & 25 & $29.1 \%$ \\
\hline Self Muttering & 25 & $29.1 \%$ \\
\hline $\begin{array}{l}\text { 2nd Person Auditory } \\
\text { Hallucination }\end{array}$ & 24 & $27.9 \%$ \\
\hline Loss of Appetite & 24 & $27.9 \%$ \\
\hline Self Withdrawal & 19 & $22.1 \%$ \\
\hline Physically Assaultive & 16 & $18.6 \%$ \\
\hline $\begin{array}{l}3^{\text {rd }} \text { Person Auditory } \\
\text { Hallucination }\end{array}$ & 12 & $14.0 \%$ \\
\hline $\begin{array}{l}\text { Delusion of } \\
\text { grandiosity }\end{array}$ & 11 & $12.8 \%$ \\
\hline Verbally Abusive & 11 & $12.8 \%$ \\
\hline Delusion of Infidelity & 8 & $9.3 \%$ \\
\hline Wandering Behavior & 7 & $8.1 \%$ \\
\hline
\end{tabular}

Most of the patients (33.7\%) had duration of illness of 1 - 5 years followed by $31.4 \%$ (27) with duration of illness being less than 1 year. 16.3\% (14) patients with 10 - 15 years of illness, $11.6 \%$ (10) with 5 - 10 years and only 7\% (6) patients with illness more than 15 years.

The duration of hospital stay was less than 30 days in $67(78 \%)$ patients while it was $31-40$ days in $10(11.6 \%)$ and more than 40 days in only $9(10.5 \%)$ patients.

\section{DISCUSSION:}

Looking at demography of patients enrolled, it was seen that male patients were almost $2 / 3^{\text {rd }}$ of total. That could be due to males getting better attention in families for treatment. Most of them were of younger age group, unmarried, from low socio economic status, hindu by religion, Brahmins by caste. These findings are consistent with findings of earlier studies in the country. ${ }^{2-6}$
Out of the 86 patients, $15(17.4 \%)$ had at least one suicidal attempt. Substance use was found in $37(43 \%)$ patients, with nicotine in $33(38.4 \%)$ patient, alcohol in $22(25.6 \%)$ patients and cannabis in $13(15.1 \%)$ patients. It is a known fact that suicide and substance use are common in patients with psychotic disorders which was seen in this study also. 7,8

Among 86 cases, 26(30.2\%) were diagnosed as Unspecified nonorganic psychosis, $24(27.9 \%)$ as Schizophrenia, $19(22.1 \%)$ as Schizoaffective disorder, $14(16.3 \%)$ as Acute \& Transient Psychotic Disorder, 3(3.5\%) as Persistent delusional disorder according to the International Classification of Disease (ICD-10) ${ }^{9}$ of mental and behavioral disorders. Unspecified psychosis seems to be the most common diagnosis which might be due to inadequacy of information.

Among the psychotic symptoms, Delusion of persecution was most common followed by delusion of reference, $2^{\text {nd }}$ person auditory hallucination, $3^{\text {rd }}$ person auditory hallucination. In a study done by Sapkota $\mathrm{N}$ et al and Ranjan $\mathrm{S}$ et al also, delusion of persecution was most common psychopathology. ${ }^{6}$

Among the total number of patients, 40 (46.5\%) had insidious onset, $35(40.7 \%)$ had acute onset and $11(12.8 \%)$ had abrupt onset of the illness. The course of the illness was continuous in 72 $(83.1 \%)$ patients, continuous with waxing and waning in $5(5.8 \%)$ patients, episodic with complete inter-episodic remission in 7 (8.1\%) patients and episodic with incomplete interepisodic remission in $2(2.3 \%)$ of them. This is also the usual feature of psychotic illnesses.

Only $31.4 \%$ (27) had duration of illness less than 1 year, which shows that people have poor awareness about psychiatric illnesses and seek treatment after significant delay. This finding is consistent with a study from India. ${ }^{10}$

\section{CONCLUSION:}

Most of the cases were of younger age group, from low middle socio economic family. Most common diagnosis among psychotic disorders was unspecified psychosis followed by schizophrenia. Commonest psychotic symptom was delusion of persecution followed by delusion of reference and auditory 
hallucinations. Also, there is delay in accessing treatment among patients with psychosis.

\section{ACKNOWLEDGEMENT: None}

\section{CONFLICT OF INTEREST: None}

\section{REFERENCES:}

1. World Health Organization. Mental Disorders. Schizophrenia and other Psychoses. Geneva: WHO April 2017. Available from URL: http://www.who.int/news-room/factsheets/detail/schizophrenia

2. Koirala NR, Yadav $R$ et al. A study of sociodemographic and diagnostic profile of patients attending the psychiatric out-patient department of Nobel Medical College, Biratnagar. Journal of Nobel Medical College. 2012; 45-49

3. Banerjee $I$ et al. Socio demographic profile and utilization pattern of antipsychotic drugs among schizophrenic inpatients: a cross sectional study from western region of Nepal. BMC Psychiatry 2013, 13:96

4. Mishra SK, Pandey AK, Adhikari BR, Nepal S. Caregiver burden and coping strategies in schizophrenia: a hospital based study. J Psychiatrists' Association of Nepal. Vol. 5, No.1, 2016

5. Ranjan $S$ et al. Clinico-demographic profile of patients with acute and transient psychotic disorders. Vol. 10 (No.3); 215-219, September-December 2012

6. Sapkota N, Shakya DR, Adhikari BR et al. Magicoreligious Beliefs in Schizophrenia: A study from Eastern part of Nepal. Journal of College of Medical Sciences, Nepal. Vol. 12, No 4, Oct-Dec 016

7. Sadock BJ, Sadock VA. Kaplan and Sadock's Synopsis of Psychiatry. 11 th ed. Philadelphia: Lippincott Williams and Wilkins; 2015. p.302

8. Sadock BJ, Sadock VA. Kaplan and Sadock's Synopsis of Psychiatry. 11 th ed. Philadelphia: Lippincott Williams and Wilkins; 2015. p.765

9. World Health Organization. International Classification of Disease and Related Health ProblemsTenth Revision. Mental and Behavioral Disorders: Clinical Description and Diagnostic Guidelines. Geneva: World Health Organization, 1992

10. Thirthalli $J$ et al. Prospective study of duration of untreated psychosis and outcome of never-treated patients with schizophrenia in India. Indian J Psychiatry. 2011 Oct-Dec; 53(4): 319-323. 